\title{
Uma experiência reflexiva sobre o processo de escrita de crônicas no ensino fundamental
}

\author{
Jaíne de Sousa Barbosa ${ }^{1}$ \\ Jéssica Pereira Gonçalves ${ }^{2}$ \\ Márcia Candeia Rodrigues ${ }^{3}$
}

\begin{abstract}
Resumo: A escrita é um dos conteúdos mais estudados no âmbito das pesquisas relacionadas ao ensino de língua portuguesa, isso porque são muitos os aspectos envolvidos nesse árduo e complexo processo. Esta é uma das muitas pesquisas que se dedicam a estudar a escrita. Nosso objetivo é relatar como ocorreu o trabalho com a escrita do gênero crônica em uma turma de $9^{\circ}$ ano de uma escola pública do município de Campina grande durante a vigência de 20 aulas correspondente ao cumprimento de uma das atividades do componente curricular Estágio de língua portuguesa, da UFCG. Destacaremos, nas páginas que seguem como ocorreu o estudo do gênero e a produção escrita deste, cujo objetivo era concorrer à Olimpíada de língua portuguesa (2014). Apoiando-nos na perspectiva sociointeracionista e dessa forma considerando o texto enquanto processo, apresentaremos como ocorreu cada etapa do processo de escrita: o planejamento, a escrita propriamente dita e a reescrita, através das atividades propostas e de duas versões da produção escrita de um dos alunos: a produção inicial e a final. Baseamo-nos nas pesquisas realizadas por autores como Barbeiro (2007), Antunes (2003), Passareli (2004), dentre outros teóricos que muito nos acrescentam sobre o processo de escrita.
\end{abstract}

Palavras- chave: Ensino; Escrita; Crônica.

\section{A reflective experience about the writting process of chronics in elementary school}

\begin{abstract}
Writing is one of the most studied subject about teaching Portuguese language; because there are so many aspects inside this hard and complex process. This is one of these papers dedicated to study the writing. Our goal is to report how was the work with writing the chronicle genre in a class of 9th grade in a public school at Campina Grande city. It had the duration of 20 classes which correspond to the performance of one of the activities of the curricular component Estágio de Língua Portuguesa at UFCG. In this paper, we are going to highlight how was the study of the genre, and how was the writing production, whose goal was to compete for Portuguese Olympics (2014). Relying on a sociointeractionist perspective and thus considering the text as a process, we are going to present how was every step of the writing process: planning, writing and rewriting itself, through the proposed activities and two version of the chronicle: the inicial and final one. We rely on searches made by authors such as Barber (2007), Ali (2003), Passareli (2004), among other authors that really increased our knowledge about the writing process.
\end{abstract}

Key words: Teaching; Writing; Chronic

\footnotetext{
${ }^{1}$ Graduanda do curso de Letras-português, da Universidade Federal de Campina Grande. E-mail: jessica.pgs2@hotmail.com

${ }^{2}$ Graduanda do curso de Letras-português, da Universidade Federal de Campina Grande. E-mail: jaine.barbosa_@outlook.com

${ }^{3}$ Professora, doutora da Unidade Acadêmica de Letras (UAL) da Universidade Federal de Campina grande. E-mail: marciac_rodrigues@ @otmail.com
} 


\section{INTRODUÇÃO}

A prática docente é alvo de várias investigações. Busca-se compreender como o ensino é concebido, quais os paradigmas que o norteia, quais os conteúdos aplicados, como esses conteúdos são repassados aos discentes e principalmente qual o papel do professor e do aluno enquanto eixos primordiais para que a aprendizagem ocorra.

A escrita, que norteia grande parte das atividades em sala, é o conteúdo que será aqui observado; uma vez que nas atividades em que ela está inserida percebemos que enxergá-la como processo é algo imprescindível. Esse processo, que é realizado através da sequência didática, inclui o planejamento, em que as ideias centrais do texto são organizadas; a produção inicial, na qual o aluno escreve a primeira versão de seu texto; a reescrita, que tem por meta sanar os problemas encontrados na primeira produção elaborada; e, por fim, a produção final, que traz as ideias centrais melhor organizadas e os problemas, que envolvem os aspectos relacionados à coesão, à coerência e ao código linguístico, parcialmente resolvidos.

Além de pensarmos nesse processo, é necessário, portanto, que busquemos compreender o que é o ensino de escrita na escola, já que essa prática tem sido enxergada simplesmente quanto ao conteúdo linguístico. Fato que, incoerentemente, gera no aluno a certeza de que seu texto receberá maior pontuação se não apresentar erros gramaticais, próprios do código da língua.

Pensar na atividade de escrita, atribuindo a ela a visão de processo e não de produto, é algo que requer do professor o preparo para levar seu aluno a compreender a importância de conceber seu texto como um material que é escrito com um objetivo, para um determinado leitor, em uma circunstância; e não como um amontoado de ideias e frases desconexas. Além disso, para observar o que é ensinar a escrita na escola e como essa escrita acontece, é preciso pensar o texto em instâncias que envolvem não só o código linguístico, mas ideias, experiências, opiniões e pensamentos próprios de sujeitos que põem no texto o seu modo de ver o mundo.

Esse trabalho é um relato de experiências fruto das observações colhidas durante o período de 20 (vinte) aulas no $9^{\circ}$ ano do ensino fundamental em uma escola do município de Campina Grande. Tal atividade foi sugerida no decorrer no componente curricular Estágio de Língua Portuguesa, ofertada pelo curso de Letras- Língua Vernácula, no período 2014.1, da Universidade Federal de Campina Grande. No âmbito 
desse trabalho, buscaremos, como objetivo principal, observar o que é o ensino de escrita na escola, como funciona o processo de produção de um texto e como se deu o processo de produção textual escrita durante as aulas ministradas, já que a escola em questão estava participando de uma Olimpíada de Língua Portuguesa que tem por meta desenvolver a capacidade de escrita dos alunos.

Levando em consideração a escrita, enquanto processo, e seguindo as orientações propostas nas sequências didáticas, que buscavam orientar os educandos quanto às atividades voltadas ao gênero crônica, discutiremos aqui o resultado das etapas que foram cumpridas: a apresentação inicial, a elaboração da primeira versão do texto, a resolução de módulos que visaram sanar os problemas encontrados nas produções e, por fim, a produção final.

Buscaremos unir os aportes teóricos escolhidos, mencionados abaixo, com as aulas e atividades realizadas durante o estágio, de modo a observarmos como ocorreu a relação entre teoria sobre processo de produção textual escrita e prática na sala de aula. Traremos as atividades por nós elaboradas, as crônicas lidas em sala, que auxiliaram na compreensão desse gênero, e as versões das produções textuais elaboradas por alguns alunos da turma.

Para fundamentarmos nossa pesquisa buscamos as considerações de Pimenta e Gonçalves (2004), acerca da experiência de estágio; de Barbeiro \& Pereira (2007), que nos auxiliaram quanto à compreensão da complexidade que é produzir um texto por meio de etapas; as considerações de Antunes (2003), sobre a exploração do ato de escrever; as informações de Santos, Riche \& Teixeira (2012), que nos dizem sobre a produção de textos orais e escritos e as contribuições de Koch e Elias (2009), Passareli (2004) sobre o ato de ler e escrever, Steuk e Heinig (2008) sobre a escrita na escola; Soares (2003), sobre o que é letramento; e Lerner (2002), sobre o que é ler e escrever na escola.

\section{Apontamentos teóricos: $O$ que é ensinar a escrita na escola?}

Pensar no ensino de escrita na escola é algo que requer muito mais do que a compreensão do código linguístico. Para que a escrita seja trabalhada no ambiente escolar é necessário, antes de tudo, que seja rejeitada a ideia de que a essa atividade é 
apenas um produto. É essencial que os alunos a reconheçam como um processo que não abarca somente o conteúdo linguístico.

Segundo Steuck \& Heinig (2008. p.3), “a escrita na escola, de acordo com o que se depreendeu dos dizeres dos sujeitos, está ainda ligada às questões gramaticais e à correção". E esse fato é um grave problema, uma vez que gera no aluno a certeza de que seu texto será "bom" caso não apresente nenhuma inadequação no que se refere aos aspectos gramaticais. É por esse motivo que deve ser excluída a noção de texto como simplesmente código, visão essa que foi implantada nas escolas desde muito e que torna o exercício de escrita puro treino. Magda Soares (2003), em um texto acerca do letramento mostra-nos que é imprescindível entender que ensinar a escrita na escola é ensinar a escrever em um contexto em que essa atividade, juntamente com a leitura, façam parte da vida do aluno e proporcione a esse a desenvoltura de suas habilidades e competências pragmático-textuais, além, é claro, das léxico-gramaticais, que não se dissociam da primeira.

Interessa ao aluno e ao professor saber que "a atividade de escrita envolve aspectos de natureza variada (linguística, cognitiva, pragmática, sócio histórica e cultural) (KOCH; ELIAS, 2009, p.31). A partir do momento em que o aluno passa a enxergar a escrita dessa forma ela terá sido apreendida, e a partir do momento em que o professor mostrar essa concepção de escrita, ela será ensinada no ambiente escolar. Não basta somente que informações sejam repassadas. É necessário, sobretudo, a prática de produção textual; o exercício diário de elaboração dos mais variados tipos e gêneros textuais.

Além de ensinada, a escrita deve ser compreendida em seus aspectos, uma vez que existem inúmeras indagações sobre o que é essa prática e como ela acontece. Koch e Elias (2009, p.32) nos trazem uma explanação coerente sobre as definições dadas à escrita. As considerações elencadas demonstram que embora haja complexidade quanto às definições, seu eixo central está voltado para a linguagem, não somente em seu aspecto linguístico, mas também ao que está além disso, uma vez que os fatores externos a língua são grandes influentes no processo de elaboração de textos. Vejamos:

Apesar da complexidade que envolve a questão, não é raro, quer em sala de aula, quer em outras situações de dia a dia, nos depararmos com definições de escrita, tais como: "escrita" é inspiração"; "escrita é uma atividade para alguns poucos privilegiados (aqueles que nascem com esse dom e se transformam em escritores renomados)"; "escrita é 
expressão do pensamento"; "escrita é trabalho" que requer a utilização de diversas estratégias da parte do produtor. Essa pluralidade de respostas nos faz pensar que o modo pelo qual concebemos a escrita não se encontra dissciado do modo pelo qual entendemos a linguagem, o texto e o sujeito que escreve. Em outras palavras, subjaz uma concepção de linguagem, de texto e de sujeito escritor ao modo pelo qual entendemos, praticamos e ensinamos a escrita, ainda que não tenhamos consciência disso (KOCK; ELIAS, 2009, p.32).

É afirmado, conforme mencionamos anteriormente, que ao concebermos concepções sobre a escrita não devemos dissociá-las do modo pelo qual compreendemos a linguagem. A escrita é uma manifestação da linguagem e essa manifestação está perpassada por inúmeras influências que não só o código. Se o aluno enxerga a escrita como pura e simples decodificação de ideias, essa atividade não passará de treino escolar e será válida somente no momento em que está sendo exercitada, principalmente pelo fato de que, na maioria das vezes, o aluno, no ambiente escolar, não produz por prazer, mas em busca de pontuação e aprovação. Ele é, inúmeras vezes, direcionado a escrever para obter uma nota e essa nota será avaliada conforme os erros e acertos gramaticais, em grande parte, e outros voltados aos sentidos do texto.

Ensinar a escrita na escola é buscar levar o aluno a pensar o texto e pensar no texto, naquilo que ele organizará, incluirá e proporá em suas análises. É necessário que o professor enxergue o texto de seu aluno não como um produto pronto, acabado e passível de correções ortográficas e gramaticais. O educador, enquanto mediador, deve atuar de modo a levar o educando a imaginar o texto enquanto processo. Vejamos:

O necessário é fazer da escola uma comunidade de leitores que recorrem aos textos buscando resposta para os problemas que necessitam resolver, tratando de encontrar informação para compreender melhor algum aspecto do mundo que é o objeto de suas preocupações, buscando argumentos para defender uma posição com a qual estão comprometidos, ou para combater outra que consideram perigosa ou injusta, desejando conhecer outros modos de vida, identificar-se com outros autores e personagens ou se diferenciar deles, viver outras aventuras, inteirar-se de outras histórias, descobrir outras formas de utilizar a linguagem para criar novos sentidos... O necessário é fazer da escola uma comunidade de escritores que produzem seus próprios textos para mostrar suas ideias, para informar sobre fatos que os destinatários necessitam ou devem conhecer, para incitar seus leitores a empreender ações que consideram valiosas, para convencê-los da validade dos pontos de vista ou das propostas que tentam promover, para protestar ou reclamar, para compartilhar com os demais uma bela frase ou um bom escrito, para intrigar ou fazer rir... O necessário é fazer da escola um âmbito onde leitura e escrita sejam práticas vivas e vitais, onde ler e escrever sejam instrumentos poderosos que permitem repensar o mundo e reorganizar o próprio 
pensamento, onde interpretar e produzir textos sejam direitos que é legítimo exercer e responsabilidades que é necessário assumir. (LIMA; FERREIRA, 2010, p.4 Apud LERNER, 2002, p. 17,18)

$\mathrm{O}$ que os autores acima mencionados afirmam condiz com nosso pensamento sobre como a escrita deve ser ensinada na escola e como o objetivo de tornar o escritor autônomo, influente, pensante é importante para a desenvoltura do aluno. Quando esse tipo de escrita, que mostra ideias originais, vivas e vitais, conforme lemos, for exercitada, teremos alunos dispostos a compreender e exercitar o processo complexo que é produzir um texto coeso e coerente. E teremos professores que olharão para o texto não como um amontoado de erros gramaticais, mas como um conjunto singular de ideias a serem reorganizadas e aprimoradas.

Se levarmos em consideração o que os Parâmetros Curriculares Nacionais apontam sobre o modo pelo qual o professor deve avaliar as atividades realizadas por seus alunos, poderemos notar que o documento aponta para a importância de o professor estar preparado para atuar de modo significativo em sala. Não basta que ao aluno sejam repassados conteúdos. É necessário, sobretudo, que o educador seja e esteja sempre em processo de capacitação para que possa contribuir na formação de seu alunado, bem como afirma este documento:

\begin{abstract}
Além de uma formação inicial consistente, é preciso considerar um investimento educativo contínuo e sistemático para que o professor se desenvolva como profissional de educação. $O$ conteúdo e a metodologia para essa formação precisam ser revistos para que haja possibilidade de melhoria do ensino. A formação não pode ser tratada como um acúmulo de cursos e técnicas, mas sim como um processo reflexivo e crítico sobre a prática educativa. Investir no desenvolvimento profissional dos professores é também intervir em suas reais condições de trabalho. (BRASIL, 1997, p.22)
\end{abstract}

Levando em consideração o objetivo geral do documento para com o ensino como um todo, percebemos que existe uma busca pelo ensino que "garanta as aprendizagens essenciais para a formação de cidadãos autônomos, críticos e participativos, capazes de atuar com competência, dignidade e responsabilidade na sociedade em que vivem (BRASIL, op cit, p.24)". Essa meta também abarca o ensino de escrita, uma vez que essa atividade despertará a autonomia, o pensamento crítico do aluno e sua capacidade de desenvolver habilidades e competências variadas. Se o professor se norteia pelo documento, a produção de textos terá uma nova compreensão e 
passará de produto para processo e de simplesmente código para construção e interação de ideias.

Além de pensar nessa escrita o professor precisa reconhecer o modo pelo qual avaliará o texto do seu aluno. É nessa metodologia que, na maioria das vezes, o texto é visto como código linguístico e nada mais. Então, de acordo com o que estiver lá escrito, o aluno terá uma melhor nota se seu texto não apresentar tantos erros gramaticas. Para orientar a avaliação das produções textuais os PCNs também apontam qual é a melhor forma de agir para com essa instância. Segundo os organizadores, o professor deve:

\begin{abstract}
Considerar a variedade de produções realizadas pelos alunos, para que se possa ter um quadro real das aprendizagens conquistadas. Por exemplo: se a avaliação se dá sobre a competência dos alunos na produção de textos, deve-se considerar a totalidade dessa produção, que envolve desde os primeiros registros escritos, no caderno de lição, até os registros das atividades de outras áreas e das atividades realizadas especificamente para esse aprendizado, além do texto produzido pelo aluno para os fins específicos desta avaliação (Idem p.54)
\end{abstract}

É perceptível que não basta analisar só o código, mas todas as ideologias contidas no texto. O pensamento do aluno, os motivos pelo qual ele decidiu escrever de determinado modo, para quem o texto foi escrito entre outros inúmeros fatores. Ensinar a escrita é também compreender os porquês que resultaram no texto do aluno. O código compõe a produção como um todo, mas inserido nele estão as formas de expressão de um sujeito em formação. Pensar na escrita enquanto processo é essencial tanto para o professor, que participará efetivamente dessa atividade, como para o aluno, que passará a enxergar o texto não como um produto, mas como um conjunto de atividade a serem aprimoradas e construídas gradativamente. Esse processo, que perpassa todo o texto, será melhor analisado na sessão que segue, nela trataremos de forma específica como a planificação, textualização e revisão acontecem.

\title{
2.1Compreendendo o processo de escrita
}

Para entender a escrita é necessário que a consideremos como um processo, e para fazer com que os alunos compreendam como ocorre esse processo é preciso integralizá-los nele. Essa interação, realizada no ambiente escolar, possibilita a 
desenvoltura do discente e a participação do professor na absorção e apreensão do conteúdo. A concepção de escrita como atividade processual é algo que deve ser compreendido pelo aluno, ainda que comumente ele não saiba disso.

Longe de ser uma mera transcrição de algo pré-definido, o processo de escrita de um texto constitui um processo complexo: mobiliza uma variedade de componentes para formular as expressões linguísticas que figurarão no texto que é condicionado por uma variedade de fatores, cognitivos, emocionais e sociais, quando é levado à prática (BARBEIRO; PEREIRA, 2007, p. 17).

Esse processo, segundo Antunes (2003), é demarcado por quatro itens essenciais: A planificação, que consiste no planejamento dos objetivos do texto, dos recursos utilizados e das ideais que serão escritas; a textualização, que coloca em prática o que foi planejado; a revisão, que permite ao aluno a readequação do texto e possíveis correções e, por fim, a reescrita, que resultará no trabalho final: um texto organizado e elaborado de forma processual.

A escrita também é a atividade pelo qual o indivíduo expõe ideias, ideais e argumentos acerca de um determinado tema. É um processo complexo que exige de quem assim o realiza atividades em diferentes níveis, que variam da ativação de conhecimentos sobre o assunto referido e sobre o gênero de texto, à decisão sobre a integração dos conteúdos, articulando-os com outros elementos de maneira que haja organização, elaboração e interação.

Antunes (2003, p. 54), nos afirma que "a escrita compreende etapas distintas e integradas de realização (planejamento, operação/textualização e revisão), as quais, por sua vez, implicam, da parte de quem escreve, uma série de decisões”. Essas decisões levam o aluno a compreender como o tema tratado será desenvolvido, como as ideias serão organizadas na produção e como ele elaborará cada etapa do texto, já que é imprescindível que o aluno reconheça sua atividade de escrita como algo sequenciado, contextualizado e não apenas um puro treino escolar.

À medida que o docente inicia o processo de produção do texto, é relevante que a turma mobilize os conhecimentos sobre o tema. Esse momento é o que chamamos de planificação. O aluno recolherá, selecionará e organizará as informações existentes sobre o que será tratado e buscará planejar o seu texto. A atividade de planificação atua de modo a auxiliar o aluno a pensar o texto de modo organizado. Ele não escreverá aquilo que lhe vier à mente, mas o que foi escolhido e selecionado por meio dos 
critérios escolhidos para isso. Esses critérios devem levar em consideração o objetivo do texto, para quem ele será destinado e com qual finalidade.

Após a planificação temos a textualização, que é o momento em que o aluno escreve o texto propriamente dito. Nessa etapa ele colocará na produção aquilo que já foi pensado na planificação, e o professor deve auxiliar o aluno quanto aos aspectos referentes à coesão e à coerência do texto, à organização interligada das ideias, ao tipo e gênero textual que será elaborado e como o aluno deverá expor sua opinião nesse material, uma vez que "não existe a escrita 'para nada', 'para não ser ato de linguagem' (Idem, p.53)". Assim como a planificação, a textualização requer tempo e atenção tanto por parte do aluno como do professor, já que ambos estão trabalhando na construção do texto. A primeira produção será aos poucos aprimorada, mas ainda assim é necessário pensá-la de modo organizado, para que as etapas posteriores continuem sendo bem desenvolvidas.

Terminado os dois processos anteriormente citados, o professor passará a observar o texto no que diz respeito aos aspectos referentes aos sentidos do texto e ao código linguístico. É necessário que ao corrigir as produções o docente elabore módulos que visem solucionar os problemas encontrados no material, para que assim, no momento de revisão, os estudantes possam observar como sua produção foi avaliada, já que nessa etapa ele poderá fazer uma nova leitura e observar os comentários e sugestões feitas pelo educador naquilo que foi elaborado.

Por fim, temos a produção final, a reescrita do texto, em que o aluno põe em prática o que solucionou na revisão e o que vem produzindo desde a planificação. Essa condição "final", assim colocada pelo fato de que sempre haverá modificação necessária a cada leitura de um texto, depende completamente do modo como cada etapa foi cumprida. A interdependência existente entre elas possibilita a interação entre os processos de escrita e faz com que o aluno exercite essa competência de forma processual. Gradualmente isso resultará em uma produção final melhor organizada, tendo em vista a primeira versão do texto. Assim como a atividade de leitura se desenvolve com a prática de leitura, a atividade de escrita é exercitada quando o aluno apreende que escrever é um exercício diário e que não deve ser enxergado como decodificação de ideias ou mera transcrição de exercícios.

É visível, diante de tudo que aqui foi exposto, que escrever é muito mais que o próprio ato de escrita. É uma mobilização de ideias, pensamentos, conteúdos e 
ideologias que perpassam a mente do aluno. Pensar na escrita enquanto processo já é suficiente para iniciar a atividade de produção textual, uma vez que com esse conhecimento o aluno e seu professor poderão desenvolver as ideias centrais do texto com a certeza de que elas sofrerão ajustes e modificações que tornarão o texto melhor elaborado e organizado.

Na sessão que segue traremos o que foi pontuado de forma prática. Conforme mencionamos na introdução, esse trabalho é um relato de experiência; dessa forma mostraremos como o processo de produção escrita aconteceu e como cada etapa pôde ser cumprida.

\section{Aplicações: o processo de escrita posto em prática}

O período do estágio é um momento privilegiado para o docente em formação, uma vez que é através dele que o estagiário coloca em prática os ensinamentos adquiridos durante sua formação acadêmica. Dessa forma, torna-se essencial que o futuro professor consiga tirar o máximo de aprendizagem possível dessa que é, muitas vezes, a primeira experiência com o ensino em instituições regulares.

A dupla em questão lançou mão de uma única sequência didática para a aplicação dos conteúdos escolhidos a serem repassados aos alunos durante a regência das aulas. O uso dela foi primordial para que fosse realizado um trabalho sistemático e contínuo com a escrita do gênero crônica.

As estagiárias ministraram suas aulas tendo como objetivo principal a escrita da crônica. Dessa forma, no decorrer das aulas foram trabalhados os tipos de crônicas, análises e leituras de crônicas para que se pudesse analisar os aspectos estruturais e temáticos desse tipo de gênero textual. Ainda foram discutidos os conteúdos de denotação e conotação e, consequentemente, figuras de linguagem. Todos esses conteúdos que foram trabalhados durante os módulos visaram ajudar os alunos a compreender o gênero e dispor de recursos para escreverem seus textos. Eles realizaram atividades diversas, de identificação dos elementos constitucionais, temáticos e estilísticos da crônica, assim como dinâmicas e discussões orais sobre os textos lidos em sala.

Seguindo as orientações propostas pela sequência didática, foi repassado para a turma a concepção de escrita enquanto processo. No decorrer da aplicação dos módulos, 
os educandos foram orientados a observarem seus textos enquanto um processo contínuo que precisa ser aperfeiçoado a cada reescrita.

Abaixo vamos explicitar cada uma das etapas envolvidas no ato da escrita, de acordo com a vertente sociointeracionista. Como já mencionamos, a planificação, a textualização e a reescrita. Através de exemplos retirados dos módulos da sequência didática e dos textos de alguns alunos, iremos destacar como se deu cada etapa.

\subsection{Planificação: a etapa de identificação da temática e inserção do aluno no contexto de escrita.}

Para o momento de planificação foram destinados os 8 primeiros encontros. Esse período é primordial para que o processo de escrita concretize-se satisfatoriamente, pois por meio dele é que ocorre a contextualização com a temática e o gênero trabalhado. Como vemos, é através dele que os alunos têm o primeiro contato com o ato de escrita, tendo em vista que esse ato começa muito antes de se colocarem as palavras no papel.

Desde o primeiro encontro, portanto, as estagiárias tentaram inserir os alunos na temática proposta pela "Olimpíada de Língua Portuguesa". A primeira atividade sugerida por elas foi a apreciação de um vídeo intitulado Pé de pranta em - coisas que todo mundo diz no ônibus, disponível no canal Youtube. Após esse momento, houve a leitura da crônica Como comportar-se no bonde, de Machado de Assis. Com essa atividade buscamos observar a opinião dos alunos sobre as semelhanças e diferenças entre as leituras realizadas e sobre as experiências vividas por eles acerca do assunto tratado, que era o ato de andar em transportes coletivos e os transtornos ocorridos nesses locais, assim como constatamos a relação existente entre a crônica lida e o vídeo assistido, pois apesar de serem gêneros distintos e disporem de linguagens também distintas, abordavam o mesmo fato do cotidiano. Além disso, relacionamos o conteúdo visto com o tema "O lugar onde vivo", para discutirmos acerca da Olimpíada. As estagiárias levaram os alunos a perceberem que o fato relatado na crônica e no vídeo estava relacionado à temática e que eles precisavam atentar para isso quando fossem escrever os seus textos. Como era um assunto vivenciado por eles os alunos conseguiram trazer para sua realidade o que era retratado tanto no vídeo, que possuía uma linguagem comumente utilizada por eles, como no texto, no qual Machado consegue de uma maneira irônica retratar fatos que realmente acontecem no transporte 
público. Através dessas atividades as estagiárias tentaram contextualizar para os alunos a temática exigida pela "Olimpíada de Língua portuguesa".

Como se sabe essa contextualização temática é de extrema importância nessa etapa de planificação. Para finalizar esse momento as estagiárias aplicaram uma atividade de sondagem, para identificar se os alunos conseguiram ou não compreender o que estava sendo repassado por elas,

E.E.E.F.M Ademar Veloso Silveira
Disciplina: Língua Portuguesa
Nome:
01: O vídeo Pé de Pranta em: Coisas que todo mundo diz no ônibus trata de um tema
comum e que faz parte do cotidiano de muitos. Qual a sua opinião sobre o modo pelo qual o
ator trata desse tema? Tudo que ele afirma realmente acontece nos ônibus que você utiliza?
02: A crônica Como se comportar no bonde, de Machado de Assis (1998), é escrita em um
tipo de linguagem diferente do modo como Pé de Pranta organiza seu vídeo. Que tipo de
linguagem são utilizados para a elaboração de cada um deles e, na sua opinião, por quê elas
são utilizadas em situações distintas?
03: Diante do que foi visto nos dois textos, você acha que quais medidas deveriam ser
tomadas para melhorar a convivência dentro dos ônibus?
04: A crônica traz artigos que mostram o que não deve ocorrer dentro dos bondes.
Atualmente utilizamos o ônibus como transporte em nossa cidade. Se você fosse elaborar
novas "leis" de comportamento, como elas seriam?

Figura 01: Primeira atividade elabora pelas estagiárias, referente ao estudo do vídeo Coisas que todo mundo diz no ônibus e do texto Como comportar-se no Bonde, de Machado de Assis (1998)

Como podemos perceber, através das questões elaboradas, as estagiárias buscaram levar os alunos a compreenderem aspectos como a temática envolvida em ambos os gêneros textuais abordados, a linguagem utilizada em cada um dos gêneros, assim como as duas últimas questões que exigiam dos alunos um envolvimento com o tema tratado no texto escrito e no oral.

No encontro seguinte, foram discutidos com a turma os tipos de crônica e especificado qual deles estávamos solicitando para que eles escrevessem, no caso, a crônica literária. Foi entregue a turma uma tabela contendo as principais características do gênero, bem como os principais tipos de crônicas, como a narrativa, a esportiva, a jornalística entre outras. A tabela segue abaixo: 


\section{Observe as principais características do gênero crônica e alguns dos tipos de crônica existentes.}

\begin{tabular}{|c|}
\hline CARACTERÍSTICAS DA CRÔNICA: \\
$x$ Narração curta; $\boldsymbol{x}$ \\
Descreve fatos da vida cotidiana; \\
$x$ Pode ter caráter humorístico, crítico, satírico e/ou irônico; \\
$x$ Possui personagens comuns; \\
$x$ Segue um tempo cronológico determinado; $x$ \\
Uso da oralidade na escrita e fala das personagens; \\
$x$ Linguagem simples.
\end{tabular}

\section{ALGUNS TIPOS DE CRÔNICAS}

CRÔNICA DISSERTATIVA: Opinião explícita, com argumentos mais "sentimentalistas" do que "racionais" (em vez de "segundo o IBGE a mortalidade infantil aumenta no Brasil", seria "vejo mais uma vez esses pequenos seres não alimentarem sequer o corpo"). Exposto tanto na $1^{\mathrm{a}}$ pessoa do singular quanto na do plural.

CRÔNICA HUMORÍSTICA: Deve ter algo que chame a atenção do leitor, assim como um pouco de humor. É sempre bom ter poucos personagens e apresentar tempo e espaços reduzidos. A linguagem é próxima do informal. Visão irônica ou cômica de fatos apresentados.

CRÔNICA JORNALÍSTICA: Apresentação de noticias ou factos baseados no cotidiano. Pode ser policial, desportiva, etc...
CRÔNICA NARRATIVA: Tem por eixo uma história, o que a aproxima do conto. Pode ser narrado tanto na $1^{\mathrm{a}}$ quanto na $3^{\mathrm{a}}$ pessoa do singular e é comprometido com fatos cotidianos ("banais", comuns).

CRÔNICA NARRATIVO-DESCRITIVA:

É quando uma crônica explora a caracterização de seres, descrevendo-os. E, ao mesmo tempo mostra fatos cotidianos ("banais", comuns) no qual pode ser narrado em $1^{\mathrm{a}}$ ou na $3^{\mathrm{a}}$ pessoa do singular. Ela é baseada em acontecimentos diários.

REFERÊNCIA: estas informações foram organizadas pelo grupo PET-LETRAS da UFCG e sofreram modificações, por parte das estagiárias, para serem melhor compreendidas.

Figura 02: Atividade elaborada pelas estagiárias para o estudo dos tipos de crônicas

Após isso, as estagiárias deixaram claro para a turma que embora existam diversos tipos, a crônica que iria ser realizada por eles seria a crônica literária, uma vez que era esse o tipo de crônica que estava sendo solicitado pelas Olimpíadas e dessa forma foram discutidos junto com a turma os aspectos estruturais, temáticos e estilísticos que caracterizam esse gênero textual.

Ainda nessa etapa de planificação foram discutidos dois aspectos interdependentes e primordiais quando o assunto é a escrita de um gênero textual: a coesão e a coerência. Através de uma atividade coletiva, na qual era solicitado que os alunos continuassem o texto do colega, mostramos para eles que um texto só pode ser 
considerado "texto" quando suas ideias estão relacionadas, e por essa razão são dependentes sintática e semanticamente. Foi demonstrado para eles que quando as partes do todo textual não estão relacionadas temos apenas um amontoado de frases soltas que não constituem um texto, mas um retalho de ideias diversas.

Tentamos mostrar para eles que todos esses conteúdos que estavam sendo repassados contribuiriam para a escrita do gênero que ocorreria após alguns encontros. E, visamos deixar claro também que esses conteúdos iriam auxiliá-los não apenas para a escrita daquele gênero especificamente, mas para todo e qualquer ato de escrita.

Posteriormente, foi discutido em sala como se divide estruturalmente o gênero crônica. As estagiárias explicaram oque destacar na introdução, quais informações acrescentamos no desenvolvimento, Como o desfecho da obra é feito e qual a importância do título.

Após a explicitação da estrutura textual, as estagiárias destacaram também em sala as questões relacionadas ao conteúdo do gênero. O que é um fato do cotidiano? Do que se distingue da temática textual? Responder a essas questões junto com os alunos foi um momento importante para o planejamento, afinal o aluno precisa saber como irá escrever o seu texto e o quê colocar nele. Essas atividades realizadas durante a etapa de planificação visavam auxiliar o aluno quanto ao que ele iria escrever no processo de textualização, para que ele tivesse domínio sobre o processo de escrita do gênero.

A etapa de planejamento foi encerrada com a explicação da proposta de produção textual que segue abaixo:

\section{PROPOSTA DE PRODUÇÃO TEXTUAL}

Durante algumas aulas assistimos ao vídeo Pé de pranta em: coisas que todo mundo diz no onnibus, realizamos a leitura da crônica Como comportar-se no bonde, de Machado de Assis (1998), discutimos acerca do gênero tratado nos dois textos e realizamos a leitura de outras crônicas. Observamos o tempo, espaço, personagens e outros aspectos. Agora é a sua vez de produzir uma crônica, já que você está preparado para elaborar esse texto. Nessa produção você irá relatar um fato do cotidiano que represente o lugar onde você vive. Não esqueça de criar personagens, um espaço, tempo e título criativo.

Figura 03: Proposta da produção inicial

Como vemos, na proposta de produção inicial buscou-se contextualizar o aluno quanto à escrita do gênero crônica em relação aos aspectos estruturais, temáticos e estilísticos. A etapa da planificação, como nos afirma Barbeiro, Antunes e tantos outros autores 
sociointeracionistas, serve para cumprir esse papel de contextualizar o aluno sobre o contexto de escrita, para que esse saiba o que escrever, como irá escrever, assim como os objetivos que quer atingir com a sua escrita.

No tópico abaixo detalharemos a segunda etapa envolvida no processo de escrita, que é a própria textualização, momento subsequente a planificação e que terá sucesso apenas se a etapa antecedente tiver sido trabalhada de forma eficaz, eficiente.

\subsection{Textualização: o colocar das ideias no papel.}

Para a etapa de textualização foram destinadas duas aulas de 45 minutos, e foi através desse momento que os alunos realizaram a primeira versão de seus textos. $\mathrm{Na}$ aula anterior a estagiária realizou uma revisão de todo o conteúdo que estava sendo trabalhado desde o começo da regência das aulas. Foram discutidos aspectos como: características do gênero, elementos constitutivos desse tipo de texto (personagens, espaço, tempo, narrador) a importância de um título atrativo, o que é o desfecho do texto e como realizar esse desfecho, entre outros aspectos estruturais e temáticos que constituem o gênero crônica.

Após essa aula, os alunos receberam a proposta de produção inicial. A estagiária leu a proposta junto com os alunos destacando para eles que aquele era o momento de colocarem em prática todo o conteúdo estudado, assim como relembrando que eles tinham capacidade para escreverem textos coerentes, pois estavam preparados para isso.

As primeiras versões variaram tanto na estrutura quanto na temática. Entre os alunos que não produziram uma crônica e os que alcançaram esse objetivo tiveram aqueles que conseguiram produzir um texto que satisfazia as características do gênero, mas que, no entanto, não tratavam sobre um determinado fato do cotidiano relacionado à temática da Olimpíada. Abaixo temos um exemplo representativo do que relatamos acima: 


\section{PROPOSTA DE PRODUÇÃO TEXTUAL}

01: Durante algumas aulas assistimos ao video péde Prata em: Coisas que todo mundo diz no ônibus, realizamos a leitura da crônica Como se comportar no bonde, de Machado de Assis (1998), discutimos acerca do tema tratado nos dois textos e realizamos a leitura de outras crônicas. Observando o tempo, espaço, personagens e outros aspectos. Agora é a sua vez de produzir uma crônica, já que você está preparado para elaborar esse texto. Nessa produção você irá relatar um fato cotidiano que represente o lugar onde você vive. Não esqueça de criar personagens, um espaço, tempo e um título criativo.

$$
\text { (O. Pi DE MAN GA) }
$$

Em um rugar ande passoras Raderan," O vento Lapra forte a terra fria malhado do chuva, onavia uma mangueira ande étó tempa onde ninguém dava aternçais foro ela quando frassamas

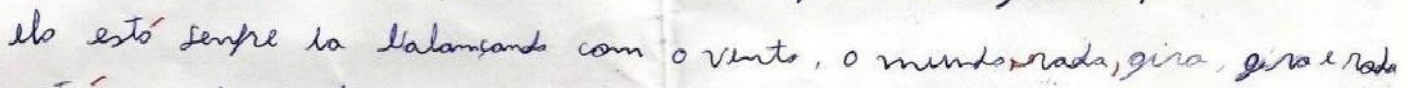
ati' ene ela Recele un fanca de água, e revigaro, donds frutas liem Lalaragos parvismoso ebsot lindo hí manga. tados ficom adimiratos carn ela hor que at um tenfs atrás ela nás dova nentum funto

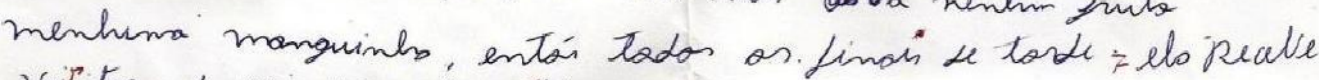
Vizitas, a criancos, fomílias inteivas give Vás horo lá fegas

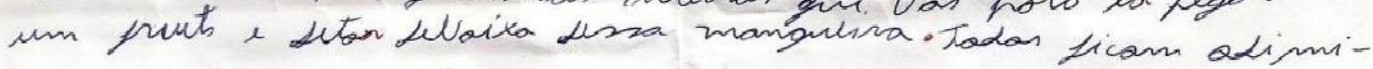

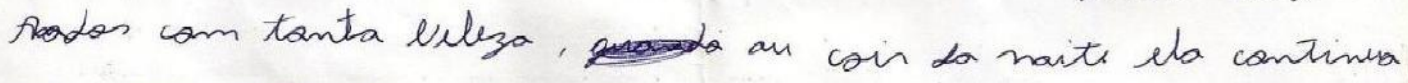
no mesmo lugar iantiaza hara amanhecen e ven cheger ma*"

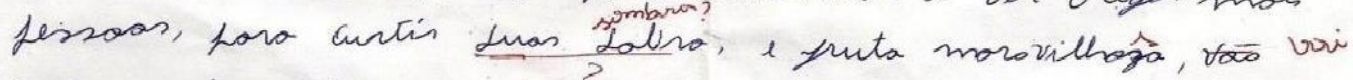
Ie hassands o tenpo l lla vai porands de dor funtas lentanente

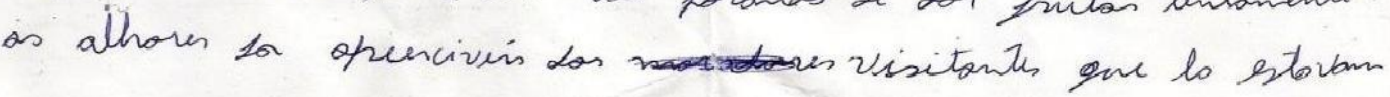

Figura 04: Produção inicial de um aluno do EF.

Como podemos perceber, o texto do aluno, embora apresente problemas de ordem linguística, é um texto bem escrito, que pode ser considerado uma crônica por trazer um fato do cotidiano e uma reflexão sobre ele. $\mathrm{O}$ aluno consegue captar um aspecto singular sobre algo que para muitos passaria despercebido, que é a importância de uma simples árvore frutífera "o pé de manga". No entanto, ele não apresenta uma reflexão sobre a temática exigida pelo concurso da "Olimpíada de Língua Portuguesa", o concurso tem como objetivo fazer com que o aluno debruce o seu olhar sobre 
determinado fato relacionado ao lugar onde ele vive, fazendo uma reflexão sobre esse fato.

Por essa razão o aluno foi orientado pelas estagiárias para reescrever o seu texto focando dessa vez o lugar onde vive, para que assim não ficasse incoerente quanto à temática exigida. No entanto, ele optou por escrever um novo texto, não utilizando mais nenhuma informação desse primeiro texto produzido na versão inicial.

A atitude do aluno é um exemplo claro de que é no momento da textualização que ocorrem as escolhas possíveis sobre o ato da escrita, podendo até ocorrer como o caso em questão, optar por escrever um texto novo, que se adéque melhor a temática. É nesse momento que o autor da escrita procura responder a questões como: qual a finalidade pretendida com a escrita de meu texto? Sendo assim, ele saberá se será adequado apenas fazer algumas alterações textuais ou se será mais apropriado escrever um texto novo.

No tópico abaixo iremos explorar sucintamente a etapa final do processo de produção textual, que é a reescrita. Iremos analisar, através da escrita do texto do mesmo aluno, como ele procedeu ao reescrever seu texto. Além disso, iremos apontar as atividades realizadas em sala, ainda nessa etapa, que visaram auxiliar os alunos na produção final.

\subsection{Etapa final: reescrita do texto.}

A etapa de reescrita do texto é um momento fundamental para o processo de produção textual. O que diferencia essa etapa das demais é que nesse momento o aluno já está preparado para fazer uma reflexão sobre o ato de escrever. Ele consegue olhar para o seu texto e perceber o que precisa ser melhorado. Muitos imaginam que a reescrita não é nada mais que passar a limpo o que foi escrito anteriormente, corrigindo apenas os erros gramaticais. No entanto, é necessário que essa visão seja desconstruída, para que se consiga chegar nesse estágio de reflexão sobre o processo de escrita é imprescindível que haja um trabalho consciente por parte do professor sobre o processo de reescrita textual.

As estagiárias, para essa etapa, desenvolveram diversas atividades com o intuito de provocar nos alunos esse olhar reflexivo sobre seus textos. A primeira dessas atividades foi a correção coletiva dos principais problemas linguísticos, textuais e temáticos 
encontrados nas produções dos alunos. Para se trabalhar problemas como coesão e coerência, a estagiária pediu para que os alunos buscassem corrigir problemas como repetições não funcionais, com a intenção de mostrar que essas repetições comprometiam o entendimento final do texto. Ainda nesse momento foram trabalhados outros problemas de ordem linguístico- textual como concordância nominal e verbal e ortografia de certas palavras. Para essa atividade as estagiárias utilizaram a louça para expor alguns fragmentos dos textos dos alunos que continham inadequações relacionadas aos aspectos acima mencionados. Esses problemas foram discutidos, pois é necessário que os alunos saibam dominar a norma culta da língua portuguesa, embora não se possa olhar apenas para esses aspectos gramaticais. Essa informação foi repassada para os alunos durante a execução da atividade.

Outra atividade proposta pelas estagiárias consistiu na aplicação de um exercício de análise dos textos produzidos pelos alunos. No exercício tínhamos questões que proporcionavam aos alunos a análise de alguns aspectos do seu texto e dos textos dos outros alunos. Observemos:

\section{Atividade}

1) Como foi destacado em sala nas aulas anteriores, o título de um texto é muito importante para que o leitor tenha interesse ou não em ler o que está escrito. Na aula anterior realizamos a primeira escrita da crônica que concorrerá a Olimpíada de Língua Portuguesa, cujo tema é "O lugar onde vivo". Leia os títulos abaixo, criados por seus colegas de classe e responda as questões abaixo:

VIDA DE GUERREIRO POR CAUSA DO BULLY, VIREI UM ATLETA

NOITES DE UM VERÃO QUALQUER DO JEITO QUE MUDOU "MITOS A CERCA DA RAMADINHA"

Eles são criativos? Explique.

Se você fosse ler um texto que tivesse um desses títulos, teria curiosidade em conhecer a história? Explique o por quê.

Qual título mais chamou sua atenção? Por quê?

2) E sobre o título de seu texto responda: Foi difícil escolhê-lo? Ele chama a atenção do leitor? Por qual motivo?

03) Ainda sobre o seu texto responda as questões abaixo:

Qual (is) foram os personagens de sua história?

Em que espaço ela ocorreu?

Você destaca em seu texto o tempo no qual a história é

narrada? Qual o tipo de narrador da sua história?

Seu texto se enquadraria mais em que estilo: irônico, sentimental, crítico, humorístico, ou outro estilo? Por quê? 
Figura 05: Atividade referente à análise dos textos produzidos pelos alunos

Como vemos, uma das questões era destinada a análise dos títulos de alguns dos textos produzidos em sala. Os alunos eram questionados sobre a pertinência dos títulos, se estavam chamativos e atraentes. As outras questões estavam relacionadas à análise dos elementos constitutivos dos textos dos alunos. Eles foram questionados sobre os elementos constitutivos da crônica, como personagens, tempo, espaço, narrador, desfecho. A atividade foi pertinente para que os alunos pudessem debruçar um olhar reflexivo sobre o texto de seus colegas e sobre seus próprios textos, além disso as estagiárias puderam esclarecer as dúvidas que os discentes tinham sobre os elementos constitutivos da narrativa.

Foi realizado ainda junto com a turma a leitura e discussão sobre a crônica Peladas, do autor Armando Nogueira. Essa crônica foi escolhida, pois tratava sobre um assunto que atrai a atenção dos alunos: o futebol. Além desse aspecto a crônica utiliza uma linguagem fortemente poética, empregando vida ao objeto descrito, no caso a bola de futebol.

Após a leitura da crônica, a estagiária destacou para a turma informações sobre os elementos constitutivos do gênero e sobre a utilização da linguagem no texto em questão. Foi destacado que o cronista descreve um fato comum do cotidiano empregando a esse uma forma curiosa de destacá-lo, o que acaba diferenciando o texto literário de um texto objetivo, que apenas descreve o real. Posteriormente, a turma realizou uma atividade de análise sobre a crônica. Vejamos abaixo:

\section{ATIVIDADE DE ANÁLISE}

Após a leitura da crônica Pelada do autor Armando Nogueira responda as questões abaixo: 01-O autor Armando Nogueira escolhe o nome Pelada para ser o título de sua crônica.

Sabendo que a escolha do título é muito importante para atrair a atenção do leitor, explique se esse título chamou sua atenção e por quê.

02- Onde se passa a história? Qual o cenário?

03- Que acontecimento transformou a praça? Que recursos o autor utilizou para realçar essa transformação?

04- No sétimo parágrafo o autor se refere à bola caracterizando-a como "coitadinha". O que esse adjetivo no diminutivo sugere?

05- Que expressões do cotidiano o autor usa no oitavo parágrafo? O que ela significa? 06- Como o cronista fez o desfecho? Que impressão esse desfecho lhe causou?

07- Seja você o autor: crie um novo desfecho para a crônica 
ISSN: 2317-2347 - Vol. 6, Ano 4, No.1 - 2015

Figura 06: Atividade de Análise sobre a crônica Pelada, de Armando Nogueira

Figura 06: Atividade de análise da crônica Peladas, de Armando Nogueira

Essa atividade foi proposta pelas estagiárias para que os alunos pudessem analisar os elementos constitutivos do gênero crônica, como espaço em que ocorre a narrativa, o tempo transcorrido nela, a criação de um acontecimento transformador, de um desfecho para a obra, bem como a importância da escolha do título. Ainda buscou-se abordar aspectos mais relacionados à linguagem, como a utilização de expressões do cotidiano, uso de adjetivos e outros elementos linguísticos utilizados para realçar as informações do texto.

Como podemos perceber foram desenvolvidas diversas atividades que visaram contribuir para a reescrita dos textos dos alunos. Após o trabalho com os módulos de reescrita, adequação temática e formal, coesão e coerência, dentre outros aspectos elencados em sala, os alunos puderam adequar seus textos quanto ao que era solicitado.

Abaixo temos um dos textos produzidos pelos alunos na etapa de produção final. $\mathrm{O}$ autor desse texto foi o mesmo do texto analisado na etapa de textualização: 


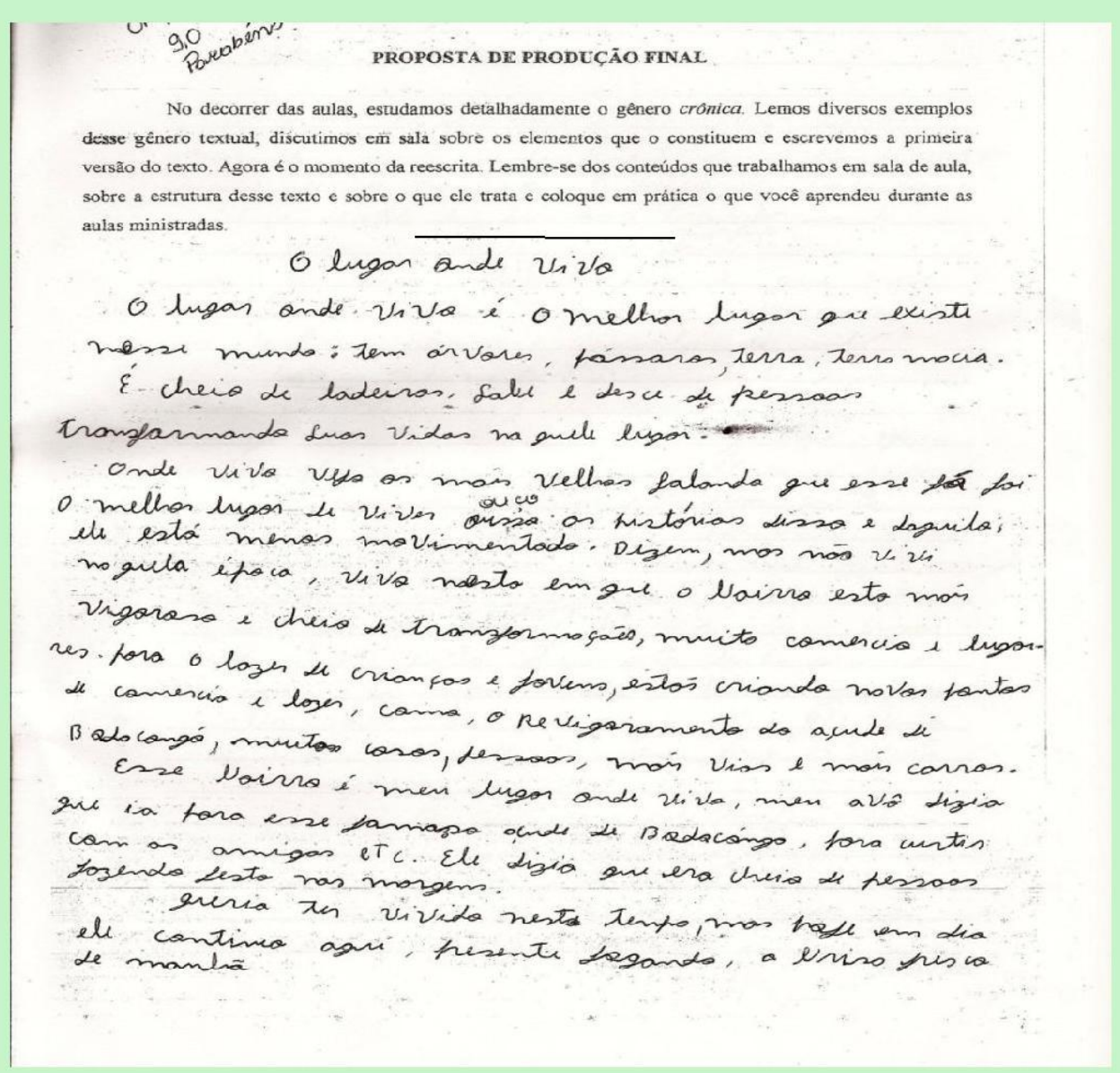

Figura 07: Produção final de um dos alunos.

Como podemos perceber, o aluno conseguiu atentar para o que foi trabalhado em sala de aula, seu texto está adequado quanto ao gênero e à temática proposta. Seu texto, que na primeira versão não estava adequado quanto à temática, na produção final, conseguiu atender a esse objetivo, constitui uma crônica que trata sobre um fato do cotidiano da cidade onde ele vive, o bairro de Bodocongó.

Os alunos no decorrer do processo de escrita da crônica puderam perceber que essa atividade é um ato comunicativo, pois é através dos textos que o ser humano expressa seus dizeres com determinado propósito, para um determinado alguém e principalmente com uma finalidade, nesse caso escrever uma crônica que poderia ser considerada a melhor de um concurso nacional e que seria lida por pessoas diversas que teriam contato com a sua escrita e seu modo de enxergar o mundo, afinal a escrita cumpre esse papel: de revelar o mundo através das palavras do autor que o observa.

\section{CONSIDERAÇÕES FINAIS}


O processo de escrita é alvo de investigações contínuas. Diversos trabalhos são realizados tendo como base norteadora os aspectos envolvidos nesse ato que é muito mais do que apenas o linguístico, mas que envolve também o social, o histórico e o ideológico. No entanto, a cada trabalho realizado sobre a escrita, mais detalhes importantes são descobertos e utilizados para acrescentar mais conhecimento sobre essa área tão importante para o universo das Letras e para as demais áreas de ensino.

Ensinar escrita ao aluno é muito mais do que ensiná-lo a colocar ideias no papel. Uma série de conhecimentos são ativados no momento da escrita. E o professor é de grande importância nessa empreitada, pois é ele o responsável por fazer com que o discente compreenda a importância desse ato de linguagem e que disponha dos recursos necessários para realizar textos dos mais diversos gêneros, com as mais distintas finalidades sociocomunicativas.

Repassar para eles um pouco sobre esse processo tão árduo e tão gratificante ao mesmo tempo foi de extrema importância para a experiência do estágio. Pudemos perceber que ensinar eficazmente as etapas do processo de escrita é indispensável para que os alunos possam compreender a importância desse ato e que adquiram um olhar de reflexão sobre os seus textos.

Através das escritas e reescritas de textos é revelado muito mais do que experiências vividas e relatadas através dos gêneros textuais, revela-nos, sobretudo, uma concepção de escrita que não aceita mais compreender o texto enquanto produto, suficiente por si só e que por isso não precisa ser reescrito. Vemos que surge, aos poucos, através da influência que os professores já atuantes e os em formação estão recebendo das teorias sociointeracionistas, a compreensão do texto enquanto processo, um processo de idas e vindas, de escritas e reescritas, árduo e gratificante para aquele que escreve.

\section{REFERÊNCIAS}

ANTUNES, Irandé. Aula de Português: Encontro e interação. Parábola Editorial. São Paulo, 2003.

BARBEIRO, Filipe e PEREIRA, Luísa Álvares. Complexidade do processo da escrita. In__. O ensino da escrita: a dimensão textual. $1^{\mathrm{a}}$ edição. Ministério da Educação Direção Geral de Inovação e de Desenvolvimento Curricular. Lisboa. 2007. 
GOULARTE, Raquel da Silva. A contribuição do Interacionismo Sociodiscursivo para $o$ ensino de Língua Portuguesa. PPGL. Disponível em <http://www.uniritter.edu.br/eventos/sepesq/vi_sepesq/arquivosPDF/27680/2221/com_i dentificacao/trabalho.pdf>Acesso em 23/Mar/13.

LERNER, Delia. Ler e Escrever na Escola: o real, o possível e o necessário, Porto Alegre, Artmed, 2002.

PASSARELLI, Lílian Ghiuro. Ensinando a escrita: o processual e o lúdico. - São Paulo: Editora Cortez, 2004.

SANTOS, Werneck Leonor. RICHE, Rosa Cuba. TEIXEIRA, Claudia Souza. Análise e produção de textos. - São Paulo: Contexto, 2012.

SOARES, Magda. O que é letramento.IN Diário na escola. São Paulo, 2003.

STEUCK, Henriette Luise. HEINIG, Otilia Lizete Martins de Oliveira. O texto em sala de aula: a voz dos professores de língua materna. Anais do CELSUL, 2008, p.3. 